\title{
Withdrawal Symptoms after Serotonin- Noradrenaline Reuptake Inhibitor Discontinuation: Systematic Review
}

\author{
Giovanni A. Fava ${ }^{a, b}$ Giada Benasi $^{a}$ Marcella Lucente ${ }^{a}$ Emanuela Offidani ${ }^{c}$ \\ Fiammetta Cosci ${ }^{d}$ Jenny Guidia

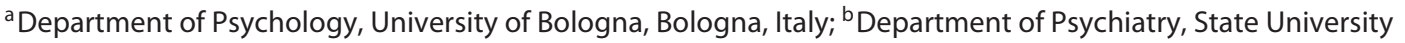 \\ of New York at Buffalo, Buffalo, NY, USA; ' $D$ Department of Behavioral Science and Education, Pennsylvania State \\ University, Schuylkill Haven, PA, USA; d Department of Health Sciences, University of Florence, Florence, Italy
}

\section{Keywords \\ Withdrawal symptoms · Serotonin-noradrenaline reuptake inhibitors · Adverse events · Discontinuation syndrome · Antidepressant drugs · Venlafaxine - Desvenlafaxine · Duloxetine $\cdot$ Milnacipran $\cdot$ Levomilnacipran}

\begin{abstract}
Background: Serotonin-noradrenaline reuptake inhibitors (SNRI) are widely used in medical practice. Their discontinuation has been associated with a wide range of symptoms. The aim of this paper is to identify the occurrence, frequency, and features of withdrawal symptoms after SNRI discontinuation. Methods: PRISMA guidelines were followed to conduct a systematic review. Electronic databases included PubMed, the Cochrane Library, Web of Science, and MEDLINE from the inception of each database to June 2017. Titles, abstracts, and topics were searched using a combination of the following terms: "duloxetine" OR "venlafaxine" OR "desvenlafaxine" OR "milnacipran" OR "levomilnacipran" OR "SNRI" OR "second generation antidepressant" OR "serotonin norepinephrine reuptake inhibitor" AND "discontinuation" OR "withdrawal" OR "rebound." Only published trials in the English language were included. Results: Sixty-one re-
\end{abstract}

๑) 2018 S. Karger AG, Basel

E-Mail karger@karger.com www.karger.com/pps ports met the criteria for inclusion. There were 22 doubleblind randomized controlled trials, 6 studies where patients were treated in an open fashion and then randomized to a double-blind controlled phase, 8 open trials, 1 prospective naturalistic study, 1 retrospective study, and 23 case reports. Withdrawal symptoms occurred after discontinuation of any type of SNRI. The prevalence of withdrawal symptoms varied across reports and appeared to be higher with venlafaxine. Symptoms typically ensued within a few days from discontinuation and lasted a few weeks, also with gradual tapering. Late onset and/or a longer persistence of disturbances occurred as well. Conclusions: Clinicians need to add SNRI to the list of drugs potentially inducing withdrawal symptoms upon discontinuation, together with other types of psychotropic drugs. The results of this study challenge the use of SNRI as first-line treatment for mood and anxiety disorders.

(c) 2018 S. Karger AG, Basel

\section{Introduction}

Withdrawal symptoms have been reported after reduction and/or discontinuation of antidepressant drugs including selective serotonin reuptake inhibitors (SSRI) 
and serotonin-noradrenaline reuptake inhibitors (SNRI) [1].

A systematic review of the literature on symptoms following discontinuation of SSRI has documented that such manifestations are actually withdrawal reactions that frequently occur even with gradual tapering of the drug [2]. Withdrawal symptoms can have either an early or a late onset, have a short or a long duration, and may be easily misinterpreted as signs of an impending relapse. SNRI have been reported to produce similar types of discontinuation/withdrawal symptomatologies $[1,3]$ and yet, to the best of our knowledge, in the English language there has not been a systematic review of the literature on the clinical aspects of SNRI discontinuation.

Such a review appears to be important in view of the fact that SNRI are increasingly prescribed [4] and usually considered the first choice in the treatment of mood and anxiety disorders, both for their efficacy and for their presumed high levels of safety and tolerability [5]. They are also employed in clinical conditions such as chronic pain, functional medical disorders, and menopausal symptoms [5].

\section{Methods}

\section{Data Sources}

PRISMA guidelines were followed to conduct a systematic review of the literature, reporting or examining the presence of SNRI withdrawal/discontinuation symptoms [6]. Electronic databases included PubMed, the Cochrane Library, Web of Science and MEDLINE from the inception of each database to June 2017. Titles, abstracts and topics were searched using a combination of the following terms: "duloxetine" OR "venlafaxine" OR "desvenlafaxine" OR "milnacipran" OR "levomilnacipran" OR "SNRI" OR "second generation antidepressant" OR "serotonin norepinephrine reuptake inhibitor" AND "discontinuation" OR "withdrawal" OR "rebound." In the Appendix (online suppl. material; see www. karger.com/doi/10.1159/000491524 for all online suppl. material), we report the search strategy that was used. In addition, reference lists and citations of initially identified reports were examined. Additional clinical trials were searched manually. Only published trials in the English language were considered for inclusion.

\section{Study Selection}

The search was carried out independently by G.B. and M.L.; disagreements were resolved by consensus among these primary raters and a senior investigator (G.A.F.). Articles were eligible if they reported at least 1 case of withdrawal syndrome after reduction or discontinuation of SNRI. Randomized controlled trials (RCT) were eligible if they compared discontinuation symptoms among groups. We included studies with various designs, such as RCT, open trials, naturalistic prospective studies, retrospective studies, and case reports, selecting only those that considered human adult (age $\geq 18$ years) subjects in a clinical setting. We exclud- ed studies in which the SNRI was administered in combination with another SNRI or another drug.

In order to obtain as much data as possible, full texts of 154 studies testing the efficacy and tolerability of SNRI were analyzed, even though they did not report information on withdrawal in their title or abstract.

\section{Data Extraction}

Data were independently extracted by both reviewers with the use of a precoded form. The following data were extracted from studies meeting the criteria for inclusion in the systematic review: study design; age and gender distribution; size and primary diagnosis of the sample; group comparisons; type, duration, dose, and modality of discontinuation of pharmacological treatment; methods used to assess withdrawal symptoms and assessment times; and rates, duration, onset, and qualitative description of withdrawal symptoms. Data about the treatment and management of withdrawal symptoms were extracted from case reports when available.

"Relapse/recurrence," "new withdrawal symptoms," "rebound," and "persistent postwithdrawal disorder" were defined according to the criteria developed by Chouinard and Chouinard [1]; relapse and recurrence are the gradual return of the original symptoms at the same intensity as before treatment, entailing a return of the same episode and a new episode of illness, respectively; new withdrawal symptoms are classic withdrawal symptoms that are new and not part of the patient's original illness; rebound symptoms are a rapid return of the patient's original symptoms at a greater intensity than before treatment; persistent postwithdrawal disorder consists of the return of the original illness at a greater intensity and/or with additional features of the illness, and/or symptoms related to emerging new disorders, which persist for at least 6 weeks after drug withdrawal. The terms "withdrawal syndromes" and "discontinuation syndromes" were considered to be equivalent.

\section{Data Synthesis}

In view of the highly heterogeneous patient populations, differences in the design of the studies and in the assessment methods of discontinuation symptoms, a meta-analysis was not deemed to be appropriate.

\section{Results}

The initial search identified 3,193 potentially relevant reports about SNRI withdrawal/discontinuation syndrome (online suppl. Fig. 1). After adjusting for duplicates, the abstract and title of 2,344 reports were screened for a first evaluation. Of these, 2,112 did not meet the inclusion criteria and were excluded, mainly because of the language, the sample (neither an adult nor a clinical population), and the involvement of psychotropic drugs other than SNRI or a combination of drugs. A detailed analysis of the full texts of the remaining 232 studies resulted in the elimination of 171 additional studies. Among the latter, 119 did not report data 
about withdrawal symptoms, 3 did not involve SNRI, 6 were reviews, 4 were posters, 1 was an abstract, 1 reported pooled data, 27 involved a combination of drugs, 2 concerned a nonclinical population, and 7 did not report data about comparisons of discontinuation symptoms among groups. One paper reported data from a post hoc analysis based on Khan et al. [7] and will be described.

A total of 61 reports met the criteria for inclusion in the systematic review. There were 22 double-blind RCT (online suppl. Table 1), 6 studies where patients were treated in an open fashion and then randomized to a double-blind controlled phase (online suppl. Table 2), 8 open trials, 1 prospective naturalistic study, 1 retrospective study (online suppl. Table 3), and 23 case reports (online suppl. Table 4).

\section{Withdrawal Symptoms in Double-Blind RCT}

Single Drug and Placebo Comparisons

Seven RCT compared a single SNRI and placebo (online suppl. Table 1).

As for duloxetine, 1 study [8] reported a significantly greater incidence of discontinuation-emergent adverse events (DEAE) in duloxetine-treated patients compared to placebo, whereas 2 trials did not $[9,10]$.

Both studies that were concerned with the use of venlafaxine $[11,12]$ reported a significantly greater incidence of DEAE in venlafaxine-treated patients compared to placebo. Symptoms commonly associated with discontinuation were headache, dizziness, nausea, lightheadedness, excessive sweating, irritability, dysphoria, and insomnia.

There were no significant differences with regard to milnacipran [13] and levomilnacipran [14] compared to placebo.

No studies used structured methods for collecting discontinuation symptoms.

Single Drug at Different Doses and Placebo

Comparisons

In 5 RCT different doses of desvenlafaxine $[15,16]$, duloxetine $[17,18]$, and venlafaxine [19] were compared with placebo (online suppl. Table 1).

In 2 studies using discontinuation-emergent signs and symptoms (DESS) [20] in major depression, the rates of discontinuation symptoms were significantly greater with $50 \mathrm{mg} /$ day desvenlafaxine than with placebo [15, $16]$.

The 2 studies that were concerned with the use of duloxetine did not use structured methods of DEAE collection. One disclosed significant differences in DEAE [18], whereas the other [17] did not.
Allgulander et al. [19] used the Benzodiazepine Withdrawal Symptoms Questionnaire [21]. We calculated a significantly higher incidence of discontinuation symptoms after extended-release (ER) venlafaxine at any dosage (52\% with $37.5 \mathrm{mg} / \mathrm{day}$, $35 \%$ with $75 \mathrm{mg} /$ day, and $78 \%$ with $150 \mathrm{mg} /$ day) compared to placebo $(\sim 12 \%)$. It was highest after abrupt discontinuation of $150 \mathrm{mg} /$ day ER venlafaxine.

\section{Multiple Drugs and Placebo Comparisons}

Five RCT compared different drugs with placebo (online suppl. Table 1$)$.

Hartford et al. [22] detected significant differences between venlafaxine (75-225 mg/day) and placebo but not between duloxetine (60-120 mg/day) and placebo in terms of rates of DEAE. Nausea and dizziness were the most frequently reported symptoms. Tourian et al. [23] compared desvenlafaxine at $50 \mathrm{mg} /$ day, desvenlafaxine at $100 \mathrm{mg} /$ day, and duloxetine at $60 \mathrm{mg} /$ day with placebo. Significantly higher mean DESS scores [20] were reported for duloxetine at $60 \mathrm{mg} /$ day and desvenlafaxine at 50 $\mathrm{mg} /$ day, and for duloxetine at $60 \mathrm{mg}$ /day and desvenlafaxine at $100 \mathrm{mg} /$ day after 1 and 2 weeks of the taper treatment period.

Goldstein et al. [24] compared duloxetine, fluoxetine, and placebo and did not find significant differences between duloxetine and placebo. Cutler et al. [25] used a modified version of the DESS [20] and found a significantly higher incidence of withdrawal symptoms in the group that received quetiapine at $150 \mathrm{mg} /$ day compared to placebo (24.3 vs. $11.5 \%$ ) during the 2 -week discontinuation/tapering phase, whereas withdrawal symptoms were not significantly higher than with placebo in the groups that received quetiapine and duloxetine at 300 $\mathrm{mg} /$ day (17.1 and $17.4 \%$, respectively). In the study of Mahableshwarkar et al. [26], who used the DESS [20], there were no significant differences between duloxetine, vortioxetine, and placebo.

\section{Multiple Drug Comparisons}

Five reports compared a single SNRI with an SSRI for the treatment of major depression (online suppl. Table 1). In 1 investigation reported in 2 papers [27, 28], paroxetine produced systematically more posttreatment emergent adverse events than milnacipran after 6 and 24 weeks of treatment.

Montgomery et al. [29] found significantly higher DESS scores in the venlafaxine group than in the escitalopram group. Unsteady gait, burning, forgetfulness, shaking, restless feeling, nausea, confusion, sweating, agita- 
tion, fatigue, and dizziness were significantly greater in the venlafaxine group. Sir et al. [30] were unable to detect significant differences between venlafaxine and sertraline, except for tremor, vertigo, and impaired coordination, which were more than twice as common in the venlafaxine group.

Wade et al. [31] did not observe significant differences between duloxetine and escitalopram, except for anxiety, which was significantly greater with escitalopram.

\section{Withdrawal Symptoms in Double-Blind RCT after \\ Open Treatment}

In a number of studies patients were treated with an SNRI in an open fashion and then randomized to double-blind drug/placebo controlled continuation (online suppl. Table 2).

\section{Single Drug at Different Doses Comparisons}

In the trial by Chappell et al. [32] patients received duloxetine at $60 \mathrm{mg} /$ day during an open-label phase of 8 weeks and were then randomized to duloxetine at 60 or $120 \mathrm{mg} /$ day for an additional double-blind period of 52 weeks. All patients receiving duloxetine 60 at $\mathrm{mg} /$ day for at least 2 weeks were encouraged to enter a 2 -week tapering period. During the tapering phase, there were no significant differences between the 2 doses.

\section{Single Drug and Placebo Comparisons}

Three reports evaluated the efficacy of SNRI in preventing relapse of major depression. In those studies an open-label treatment phase with duloxetine [33] or desvenlafaxine $[34,35]$ was followed by a double-blind RCT phase in which duloxetine or desvenlafaxine-treated patients were randomized to receiving the same dose of the study drug or placebo (online suppl. Table 2).

Spontaneous reporting did not disclose significant differences between placebo- and duloxetine-treated patients [33].

Two studies were concerned with the use of desvenlafaxine. In the study by Rickels at al. [34], DESS scores [20] were significantly higher in patients who were switched to placebo than in those who continued with desvenlafaxine. After the end of the double-blind period, taper/posttherapy-emergent adverse events were reported by $28 \%$ of the patients in the placebo group and by $53 \%$ of the patients in the desvenlafaxine-treated group [34]. Rosenthal et al. [35] relied on spontaneous reporting and were unable to detect significant differences between desvenlafaxine and placebo.
Comparisons of Different Discontinuation Methods

Two studies evaluated the tolerability of different discontinuation methods after treatment of major depression [7] and vasomotor symptoms in healthy postmenopausal women [36]. After the RCT phase, all treatments were interrupted and a follow-up evaluation was done to evaluate discontinuation symptoms (online suppl. Table 2).

In the trial by Gallagher et al. [36] the DESS total score [20] was greater the week after complete discontinuation of desvenlafaxine in each of the 4 groups, showing little benefit of the taper regimen in preventing the occurrence of discontinuation symptoms. In the study by Khan et al. [7] the DESS total score increased during the first 2 weeks of the discontinuation phase compared to baseline in all of the treatment groups, without significant differences among groups. Ninan et al. [37] conducted a post hoc analysis on these data, confirming that taper/posttherapy-emergent adverse events occurred in all 3 groups through week 4 of the discontinuation phase, regardless of whether the desvenlafaxine dose was tapered or not.

\section{Withdrawal Symptoms in Open Trials and}

\section{Naturalistic Prospective/Retrospective Studies}

Eight open-label reports evaluated the efficacy and tolerability of venlafaxine [38, 39], duloxetine [40-42], levomilnacipran [43], and desvenlafaxine [44, 45] (online suppl. Table 3).

Most venlafaxine-treated patients experienced discontinuation symptoms, with rates around $75 \%[38,39]$. In the report by Dallal and Chouinard [38], patients developed both withdrawal and rebound symptoms, including anxiety, agitation, tremors, vertigo, headache, nausea, tachycardia, tinnitus, and akathisia. In the investigation by Cohen et al. [39], the most commonly reported discontinuation symptoms were headache, vivid dreams or nightmares, sweating, muscle cramps, and trouble sleeping.

The incidence of DEAE after treatment with duloxetine at $60-120 \mathrm{mg}$ /day ranged from 9.1 to $16.2 \%$ in 2 studies [41, 42]. Raskin et al. [40] reported dizziness, anxiety, nausea, headache, insomnia, and irritability.

Discontinuation symptoms were reported by $9 \%$ of the patients during a down-taper period of up to 4 weeks after the end of the open-label treatment phase with levomilmacipran [43].

The incidence of taper/poststudy-emergent adverse events after the discontinuation of desvenlafaxine at 200$400 \mathrm{mg} /$ day ranged from 42 to $52 \%$ [44, 45]. In both studies the most common discontinuation symptoms were dizziness, nausea, and headache. 
Tint et al. [46] conducted an open randomized naturalistic prospective study to evaluate whether a short or a longer taper influences the incidence of discontinuation symptoms (online suppl. Table 3 ). Patients treated with fluoxetine, paroxetine, citalopram, fluvoxamine, or venlafaxine for at least 6 weeks were randomized to a 3-day or a 14-day taper period before starting a new antidepressant treatment. Overall, a significant increase in DESS symptoms was observed 5-7 days after tapering, without significant differences between the 2 discontinuation methods.

Baboolal [47] retrospectively reviewed the case notes of 68 patients treated with venlafaxine XR at $37.5-75 \mathrm{mg} /$ day (online suppl. Table 3). The most common discontinuation symptoms were dizziness, nausea, and headache. Other reported symptoms were fatigue, tremor, vomiting, shock-like sensations in the body, diarrhea, bizarre dreams, inability to walk unaided, insomnia, a "bad feeling," sweating, lightheadedness, fear of "going crazy," a crawling sensation on the scalp, fear, and depersonalization. These symptoms were associated with significant impairment in social and occupational functioning in all of the patients.

\section{Withdrawal Symptoms in Case Reports}

Venlafaxine

We identified 19 case reports of withdrawal symptoms in adult patients (aged 24-76 years) taking venlafaxine [48-66]. Discontinuation symptoms were reported independently of the treatment duration (from few weeks to years) and discontinuation (abrupt vs. tapered). Symptoms usually appeared within a period of $24-48 \mathrm{~h}$ after discontinuation. Venlafaxine withdrawal symptoms generally waned within a period of 3 weeks. However, there were few cases in which these symptoms lasted for months [53] or even years [64]. Only in 1 case did symptoms spontaneously remit in 4 days [59]. Venlafaxine was generally reintroduced to address these symptoms. Other management methods included fluoxetine $[48,51]$, chlorpromazine [53], ondansetron[56], sertraline [57], a low dosage of lorazepam [58], a combination of lorazepam and valproate [60], and duloxetine $[62,66]$.

\section{Duloxetine}

Three case reports of duloxetine withdrawal reactions were retrieved [67-69]. Withdrawal symptoms appeared between $36 \mathrm{~h}$ and 2 days after abrupt or tapered discontinuation of treatment. Nausea was a common symptom overall. Withdrawal symptoms were generally treated through reintroduction of duloxetine $[68,69]$ or intro- duction of a different antidepressant [67], such as fluoxetine [68] (online suppl. Table 4).

\section{Milnacipran}

Williams et al. [70] reported 1 case of acute neurological syndrome with cerebrovascular and parkinsonian clinical features after abrupt discontinuation of milnacipran. Symptoms disappeared after the reintroduction of milnacipran.

\section{Discussion}

The results of this systematic review indicate that withdrawal symptoms may occur after discontinuation of any type of SNRI (venlafaxine, desvenlafaxine, duloxetine, milnacipran, or levomilnacipran). However, the prevalence of withdrawal symptoms was variable and appeared to be higher after discontinuation of venlafaxine. The rates of withdrawal symptoms from both RCT and open trials ranged from 23 to $78 \%$ after discontinuation of venlafaxine, from 17.2 to $55 \%$ after desvenlafaxine, from 6 to $55 \%$ after duloxetine, from 13 to $30 \%$ after milnacipran, and from 9 to $10 \%$ after levomilnacipran.

In the RCT that reported data about the comparison between SNRI and placebo, withdrawal symptoms were significantly higher after discontinuation of venlafaxine $[11,12,19,22]$ and desvenlafaxine $[15,16,23,34]$, whereas they did not differ from placebo in most of the trials on duloxetine $[9,10,17,22,24-26,33]$ or in the studies on levomilnacipran [14] and milnacipran [13]. The duration of treatment with venlafaxine or desvenlafaxine was as short as 2 months [11, 15, 16, 23].

Withdrawal symptoms included a wide range of clinical manifestations (Table 1), regardless of whether gradual or abrupt discontinuations were implemented, and they were similar to those observed after discontinuation of SSRI [2]. They typically occurred within a few days from drug discontinuation and lasted a few weeks. However, episodes of a longer duration have been reported $[53,60,64,69]$, suggesting the presence of persistent postwithdrawal disorders [1]. Few studies reported data about rebound of symptoms $[19,38]$.

The interpretation of these findings is hampered by several methodological problems. Most studies lacked adequate methods of detection, such as DESS [20], and relied on spontaneous reports only, leading to an underestimation of withdrawal symptoms [1] and to difficulties in identifying the presence of new withdrawal symptoms, rebound, and persistent postwithdrawal syndromes $[1,71]$. 
Table 1. Signs and symptoms of withdrawal from SNRI

\begin{tabular}{|c|c|}
\hline System involved & Symptoms \\
\hline General & $\begin{array}{l}\text { Headache, fatigue, sweating, lethargy, arthralgia, weakness, decreased liquid } \\
\text { consumption, diaphoresis, pain, infection, malaise }\end{array}$ \\
\hline Visual & Blurred vision, visual changes \\
\hline Cardiovascular & $\begin{array}{l}\text { Dizziness, vertigo, syncope, tachycardia, palpitations, hypertension, lightheadedness, } \\
\text { stroke-like symptoms, chest pain, postural hypotension }\end{array}$ \\
\hline Gastrointestinal & $\begin{array}{l}\text { Nausea, vomiting, abdominal pain, anorexia, diarrhea, loss of appetite, esophagitis, } \\
\text { feeling of abdominal distention, increased bowel movements }\end{array}$ \\
\hline Sensory & $\begin{array}{l}\text { Electric shock sensations, tinnitus, paresthesia, hyperesthesia, buzzing noise within the } \\
\text { head, hot and cold feelings, burst of heat, pricking sensations, crawling sensations on the } \\
\text { scalp }\end{array}$ \\
\hline Neuromuscular & $\begin{array}{l}\text { Spasm, tremor, ataxia, cramps, coordination problems, unsteady gait, numbness, right } \\
\text { hemiplegia, left-biased gaze deviation, no movement in the right extremities, left hand } \\
\text { spontaneous pill-rolling type activity, tonic clonic seizures, restlessness, myoclonus }\end{array}$ \\
\hline Vasomotor & Sweating, flushing, chills \\
\hline Cognitive & Disorientation, slurred speech, confusion, decreased concentration, attention difficulties \\
\hline Affective & $\begin{array}{l}\text { Anxiety, fear, irritability, hypomania, mood swings, depersonalization, euphoria, suicidal } \\
\text { ideation, derealization, depression, dysphoria, nervousness, agitation, outbursts of anger, } \\
\text { sudden panic }\end{array}$ \\
\hline Psychotic & Visual hallucinations \\
\hline Sleep & Insomnia, nightmares, sleep problems, vivid dreams, drowsiness \\
\hline Behavioral & Impulsive attitudes, aggressive behavior \\
\hline
\end{tabular}

Nonetheless, the results of this systematic review have important clinical implications.

First, even though gradual tapering of SNRI appears to be a reasonable clinical strategy, it does not prevent the onset of withdrawal phenomena. Indeed, we do not have a clear and specific set of sociodemographic, clinical, and neurobiological characteristics that may be associated with increased vulnerability to the onset of withdrawal syndromes. Why, if we have 2 patients with the same psychiatric disorder who have been treated with the same SNRI for the same amount of time and who underwent the same modality of tapering and discontinuation, may we have the occurrence of withdrawal syndrome in one case and not in the other? And why do symptoms persist in certain cases? We urgently need studies exploring variables such as the binding characteristics of SNRI in the brain of patients undergoing tapering and discontinuation. What is the role of patients' attitudes to medication and the treatment setting $[72,73]$ ? Could manipulation of these variables modulate the intensity of withdrawal phenomena?

Second, recognition of withdrawal symptoms requires careful exploration of the potential symptomatology (Table 1) through specific questioning and/or instruments, in addition to knowledge of the pretreatment status $[1,20$,
$71,74,75]$. Symptoms may be easily misidentified as signs of relapse. Withdrawal symptoms are likely to have an early onset, while recurrent symptoms generally present with a gradual return. However, this is only a general tendency and not a rule. The clinical picture may be complicated by the fact that rebound phenomena (a rapid return and worsening of the patient's original symptoms) may also take place with SNRI. Trial designs that assess the effects of discontinuation of AD to infer the efficacy against recurrence (i.e., a significant increase in symptoms in patients whose $\mathrm{AD}$ are discontinued compared to those who continue with treatment) are flawed by a lack of consideration of withdrawal events.

Third, the appearance of withdrawal symptoms after SNRI discontinuation may be potentially related to a number of important clinical phenomena which may be subsumed under the rubric of behavioral toxicity $[71,76]$ and be interpreted according to the oppositional model of tolerance [77]. Continued drug treatment may recruit processes that oppose the initial acute effects of a drug and may lead to a loss of efficacy and/or to a treatmentunresponsive course. When the drug treatment ends, oppositional processes may operate for some time, resulting in the appearance of withdrawal symptoms and/or an increased vulnerability to relapse and/or resist treatment (if 
it is reinstituted), and/or switching to a bipolar course [77]. Replacing an SNRI with another AD or reintroducing the SNRI that was discontinued may decrease or eliminate withdrawal symptomatology. However, this is a strategy that may be advantageous in the short-term, but that may have deleterious consequences in the long run, since behavioral toxicity is a cumulative phenomenon that may occur regardless of the type of $\mathrm{AD}$ that is used [77].

Fourth, even when withdrawal symptoms are properly recognized, their clinical management is hindered by the complexity of the involved variables and the lack of appropriate research. Informing patients that the symptoms are likely to be short-lived and pose no threat may be a reassuring step [3], even though it may be misleading in certain cases and induce uncertainty and anxiety in other cases. Pharmacological strategies other than reintroducing or changing $\mathrm{AD}$ (e.g., benzodiazepines and antiepileptic drugs) have been used in case reports, yet we have no RCT that have tested management strategies against placebo [3].

Finally, a rational use of AD depends on the balance of potential benefits and adverse effects applied to the individual patient [78]. However, currently the physician prescribing SNRI is driven by an overestimated consideration of the potential benefits and neglect of the potential vulnerabilities to the adverse effects of treatment, such as dependence-and-withdrawal phenomena. This bias has been clearly outlined in 2 reviews on venlafaxine and duloxetine that have taken unpublished data into consideration and that challenge the use of SNRI as first-line treat- ment of mood and anxiety disorders [79, 80]. Our systematic review was based on published findings only and is thus likely to have underestimated the frequency and severity of withdrawal reactions, particularly with regard to the latest SNRI.

Clinicians are familiar with the withdrawal phenomena that may occur from alcohol, benzodiazepines, barbiturates, opioids, and stimulants [81]. The results of this review indicate that they need to add SNRI to the list of drugs potentially inducing withdrawal phenomena, as was found to be the case with SSRI [2], and the physician should exercise caution when prescribing them (particularly venlafaxine and desvenlafaxine) in mood and anxiety disorders. Considerable attention should also be used in the setting of chronic pain (e.g. duloxetine [82]), functional medical disorders and menopausal symptoms.

The term "discontinuation syndrome" has progressively replaced "withdrawal syndrome" in the antidepressant literature. This shift was heavily supported by the pharmaceutical industry and was aimed to emphasizing that antidepressants do not cause addiction or dependence and symptoms are substantially different from the phenomena that take place with benzodiazepines [2, 78]. The term "discontinuation syndrome" minimizes the vulnerabilities induced by SNRI and should be replaced by "withdrawal syndrome."

\section{Disclosure Statement}

The authors report no conflict of interests.

\section{References}

1 Chouinard G, Chouinard VA: New classification of selective serotonin reuptake inhibitor withdrawal. Psychother Psychosom 2015;84: 63-71.

2 Fava GA, Gatti A, Belaise C, Guidi J, Offidani E: Withdrawal symptoms after selective serotonin reuptake inhibitor discontinuation: a systematic review. Psychother Psychosom 2015;84:72-81.

3 Wilson E, Lader M: A review of the management of antidepressant discontinuation symptoms. Ther Adv Psychopharmacol 2015; 5:357-368.

4 Kantor ED, Rehm CD, Haas JS, Chan AT, Giovannucci EL: Trends in prescription drug use among adults in the United States from 1999-2012. JAMA 2015;314:1818.
5 Procyshyn RM, Bezchlibnyk-Butler KZ, Jeffries JJ: Clinical Handbook of Psychotropic drugs, ed 22. Boston, Hogrefe, 2017, pp 2229.

6 Moher D, Liberati A, Tetzlaff J, Altman DG; PRISMA Group: Methods of systematic reviews and meta-analysis: preferred reporting items for systematic reviews and meta-analyses: the PRISMA statement. J Clin Epidemiol 2009;62:1006-1012.

7 Khan A, Musgnung J, Ramey T, Messig M, Buckley G, Ninan PT: Abrupt discontinuation compared with a 1-week taper regimen in depressed outpatients treated for 24 weeks with desvenlafaxine $50 \mathrm{mg} / \mathrm{d}$. J Clin Psychopharmacol 2014;34:365-368.
8 Schagen van Leeuwen JH, Lange RR, Jonasson AF, Chen WJ, Viktrup L: Efficacy and safety of duloxetine in elderly women with stress urinary incontinence or stress-predominant mixed urinary incontinence. Maturitas 2008;60:138-147.

9 Raskin J, Wiltse CG, Dinkel JJ, Walker DJ, Desaiah D, Katona C: Safety and tolerability of duloxetine at $60 \mathrm{mg}$ once daily in elderly patients with major depressive disorder. J Clin Psychopharmacol 2008;28:32-38.

10 Rynn M, Russell J, Erickson J, Detke MJ, Ball S, Dinkel J, Rickels K, Raskin J: Efficacy and safety of duloxetine in the treatment of generalized anxiety disorder: a flexible-dose, progressive-titration, placebo-controlled trial. Depress Anxiety 2008;25:182-189. 
11 Fava M, Mulroy R, Alpert J, Nierenberg AA, Rosenbaum JF: Emergence of adverse events following discontinuation of treatment with extended-release venlafaxine. Am J Psychiatry 1997; 154:1760-1762.

12 Liebowitz MR, Asnis G, Mangano R, Tzanis E: A double-blind, placebo-controlled, parallel-group, flexible-dose study of venlafaxine extended release capsules in adult outpatients with panic disorder. J Clin Psychiatry 2009; 70:550-561.

13 Saxe PA, Arnold LM, Palmer RH, Gendreau RM, Chen W: Short-term (2-week) effects of discontinuing milnacipran in patients with fibromyalgia. Curr Med Res Opin 2012;28: 815-821.

14 Sambunaris A, Bose A, Gommoll CP, Chen C, Greenberg WM, Sheehan DV: A phase III, double-Blind, placebo-controlled, flexibledose study of levomilnacipran extended-release in patients with major depressive disorder. J Clin Psychopharmacol 2014;34:47-56.

15 Liebowitz MR, Manley AL, Padmanabhan SK, Ganguly R, Tummala R, Tourian KA: Efficacy, safety, and tolerability of desvenlafaxine $50 \mathrm{mg} /$ day and $100 \mathrm{mg} /$ day in outpatients with major depressive disorder. Curr Med Res Opin 2008 22;24:1877-1890.

16 Boyer P, Montgomery S, Lepola U, Germain J-M, Brisard C, Ganguly R, Padmanabhan SK, Tourian KA: Efficacy, safety, and tolerability of fixed-dose desvenlafaxine 50 and $100 \mathrm{mg} /$ day for major depressive disorder in a placebo-controlled trial. Int Clin Psychopharmacol 2008;23:243-253.

17 Raskin J, Pritchett YL, Wang F, D'Souza DN, Waninger AL, Iyengar S, Wernicke JF: A double-blind, randomized multicenter trial comparing duloxetine with placebo in the management of diabetic peripheral neuropathic pain. Pain Med 2005;6:346-356.

18 Koponen H, Allgulander C, Erickson J, Dunayevich E, Pritchett Y, Detke MJ, Ball SG, Russell JM: Efficacy of duloxetine for the treatment of generalized anxiety disorder: implications for primary care physicians. Prim Care Companion J Clin Psychiatry 2007;9: 100-107.

19 Allgulander C, Hackett D, Salinas E: Venlafaxine extended release (ER) in the treatment of generalised anxiety disorder: twenty-fourweek placebo-controlled dose-ranging study. Br J Psychiatry 2001;179:15-22.

20 Rosenbaum JF, Fava M, Hoog SL, Ascroft RC, Krebs WB: Selective serotonin reuptake inhibitor discontinuation syndrome: a randomized clinical trial. Biol Psychiatry 1998;44:77-87.

21 Tyrer P, Murphy S, Riley P: The Benzodiazepine Withdrawal Symptom Questionnaire. J Affect Disord 1990;19:53-61.

22 Hartford J, Kornstein S, Liebowitz M, Pigott T, Russell J, Detke M, Walker D, Ball S, Dunayevich E, Dinkel J, Erickson J: Duloxetine as an SNRI treatment for generalized anxiety disorder: results from a placebo and activecontrolled trial. Int Clin Psychopharmacol 2007;22:167-174.
23 Tourian KA, Padmanabhan SK, Groark J, Brisard C, Farrington D: Desvenlafaxine 50 and $100 \mathrm{mg} / \mathrm{d}$ in the treatment of major depressive disorder: an 8-week, phase III, multicenter, randomized, double-blind, placebo-controlled, parallel-group trial and a post hoc pooled analysis of three studies. Clin Ther 2009;31:1405-1423.

24 Goldstein DJ, Mallinckrodt C, Lu Y, Demitrack MA: Duloxetine in the treatment of major depressive disorder: a double-blind clinical trial. J Clin Psychiatry 2002;63:225-231.

25 Cutler AJ, Montgomery SA, Feifel D, Lazarus A, Aström M, Brecher M: Extended release quetiapine fumarate monotherapy in major depressive disorder: a placebo- and duloxetine-controlled study. J Clin Psychiatry 2009; 70:526-539.

26 Mahableshwarkar AR, Jacobsen PL, Chen Y, Serenko M, Trivedi MH: A randomized, double-blind, duloxetine-referenced study comparing efficacy and tolerability of 2 fixed doses of vortioxetine in the acute treatment of adults with MDD. Psychopharmacology (Berl) 2015;232:2061-2070.

27 Sechter D, Vandel P, Weiller E, Pezous N, Cabanac F, Tournoux A; study co-coordintors: A comparative study of milnacipran and paroxetine in outpatients with major depression. J Affect Disord 2004;83:233-236.

28 Vandel P, Sechter D, Weiller E, Pezous N, Cabanac F, Tournoux A, Panconi E: Post-treatment emergent adverse events in depressed patients following treatment with milnacipran and paroxetine. Hum Psychopharmacol Clin Exp 2004; 19:585-586.

29 Montgomery SA, Huusom AKT, Bothmer J: A Randomised study comparing escitalopram with venlafaxine XR in primary care patients with major depressive disorder. Neuropsychobiology 2004;50:57-64.

30 Sir A, D'Souza RF, Uguz S, George T, Vahip S, Hopwood M, Martin AJ, Lam W, Burt T: Randomized trial of sertraline versus venlafaxine XR in major depression: efficacy and discontinuation symptoms. J Clin Psychiatry 2005;66:1312-1320.

31 Wade A, Gembert K, Florea I: A comparative study of the efficacy of acute and continuation treatment with escitalopram versus duloxetine in patients with major depressive disorder. Curr Med Res Opin 2007;23:1605-1614.

32 Chappell AS, Littlejohn G, Kajdasz DK, Scheinberg M, D'Souza DN, Moldofsky H: A 1-year safety and efficacy study of duloxetine in patients with fibromyalgia. Clin J Pain 2009;25:365-375.

33 Perahia DGS, Maina G, Thase ME, Spann ME, Wang F, Walker DJ, Detke MJ: Duloxetine in the prevention of depressive recurrences: a randomized, double-blind, placebo-controlled trial. J Clin Psychiatry 2009;70:706716.
34 Rickels K, Montgomery SA, Tourian KA, Guelfi JD, Pitrosky B, Padmanabhan SK, Germain JM, Leurent C, Brisard C: Desvenlafaxine for the prevention of relapse in major depressive disorder. J Clin Psychopharmacol 2010;30:18-24.

35 Rosenthal JZ, Boyer P, Vialet C, Hwang E, Tourian KA: Efficacy and safety of desvenlafaxine $50 \mathrm{mg} / \mathrm{d}$ for prevention of relapse in major depressive disorder. J Clin Psychiatry 2013;74:158-166.

36 Gallagher JC, Strzinek RA, Cheng RJ, Ausmanas MK, Astl D, Seljan P: The effect of dose titration and dose tapering on the tolerability of desvenlafaxine in women with vasomotor symptoms associated with menopause. J Womens Health 2012;21:188-198.

37 Ninan PT, Musgnung J, Messig M, Buckley G, Guico-Pabia CJ, Ramey TS: Incidence and timing of taper/posttherapy-emergent adverse events following discontinuation of desvenlafaxine $50 \mathrm{mg} / \mathrm{d}$ in patients with major depressive disorder. Prim Care Companion CNS Disord 2015, 17.

38 Dallal A, Chouinard G: Withdrawal and rebound symptoms associated with abrupt discontinuation of venlafaxine. J Clin Psychopharmacol 1998;18:343-344.

39 Cohen LS, Soares CN, Lyster A, Cassano P, Brandes M, Leblanc GA: Efficacy and tolerability of premenstrual use of venlafaxine (flexible dose) in the treatment of premenstrual dysphoric disorder. J Clin Psychopharmacol 2004;24:540-543.

40 Raskin J, Goldstein DJ, Mallinckrodt CH, Ferguson MB: Duloxetine in the long-term treatment of major depressive disorder. J Clin Psychiatry 2003;64:1237-1244.

41 Raskin J, Wang F, Pritchett YL, Goldstein DJ: Duloxetine for patients with diabetic peripheral neuropathic pain: a 6-month open-label safety study. Pain Med 2006;7:373-385.

42 Perahia DGS, Quail D, Gandhi P, Walker DJ, Peveler RC: A randomized, controlled trial of duloxetine alone vs. duloxetine plus a telephone intervention in the treatment of depression. J Affect Disord 2008;108:33-41.

43 Mago R, Forero G, Greenberg WM, Gommoll C, Chen C: Safety and tolerability of levomilnacipran ER in major depressive disorder: results from an open-label, 48-week extension study. Clin Drug Investig 2013;33:761-771.

44 Tourian KA, Pitrosky B, Padmanabhan SK, Rosas GR: A 10-month, open-label evaluation of desvenlafaxine in outpatients with major depressive disorder. Prim Care Companion CNS Disord 2011, 13.

45 Ferguson JM, Tourian KA, Rosas GR: Highdose desvenlafaxine in outpatients with major depressive disorder. CNS Spectr 2012;17: 121-130.

46 Tint A, Haddad PM, Anderson IM: The effect of rate of antidepressant tapering on the incidence of discontinuation symptoms: a randomised study. J Psychopharmacol 2008;22: 330-332. 
47 Baboolal NS: Venlafaxine withdrawal syndrome: report of seven cases in Trinidad. J Clin Psychopharmacol 2004;24:229-231.

48 Haddad P, Devarajan S, Dursun S: Antidepressant discontinuation (withdrawal) symptoms presenting as "stroke." J Psychopharmacol 2001;15:139-141.

49 Benazzi F: Venlafaxine withdrawal symptoms. Can J Psychiatry 1996;41:487-487.

50 Farah A, Lauer TE: Possible venlafaxine withdrawal syndrome. Am J Psychiatry 1996;153: 576.

51 Giakas WJ, Davis JM: Intractable withdrawal from venlafaxine treated with fluoxetine. Psychiatr Ann 1997;27:85-92.

52 Jacobson N, Weiber R: Possible delayed venlafaxine withdrawal reaction: two case reports. Eur Psychiatry 1997;12:372-373.

53 Boyd IW: Venlafaxine withdrawal reactions. Med J Aust 1998;169:91-92.

54 Johnson H, Bouman WP, Lawton J: Withdrawal reaction associated with venlafaxine. BMJ 1998;317:787.

55 Parker G, Blennerhassett J: Withdrawal reactions associated with venlafaxine. Aust NZ J Psychiatry 1998;32:291-294.

56 Raby WN: Treatment of venlafaxine discontinuation symptoms with ondansetron. J Clin Psychiatry 1998;59:621-622.

57 Luckhaus C, Jacob C: Venlafaxine withdrawal syndrome not prevented by maprotiline, but resolved by sertraline. Int J Neuropsychopharmacol 2001;4:43-44.

58 Reeves RR, Mack JE, Beddingfield JJ: Shocklike sensations during venlafaxine withdrawal. Pharmacotherapy 2003;23:678-681.

59 Hsiao MC, Liu CY: Withdrawal reactions associated with low-dose venlafaxine treatment in a patient with premenstrual dysphoric disorder. J Clin Psychiatry 2004;65:1147-1148.

60 Khazaal Y: Mania after venlafaxine withdrawal in a patient with generalized anxiety disorder. Ann Pharmacother 2007;41:359-360

61 Stone TE, Swanson C, Feldman MD: Venlafaxine discontinuation syndrome and suicidal ideation. J Clin Psychopharmacol 2007;27: 94-95.
62 Hsiao MC, Liu CY: Successful duloxetine use to prevent venlafaxine withdrawal symptoms. Prog Neuropsychopharmacol Biol Psychiatry 2008:32:576.

63 Kotzalidis G, de Pisa E, Patrizi B, Savoja V, Ruberto G, Girardi P: Similar discontinuation symptoms for withdrawal from medium-dose paroxetine and venlafaxine after nine years in the same patient. J Psychopharmacol 2008;22: 581-584.

64 Clewes J: A Case Report of Onset of Tinnitus Following Discontinuation of Antidepressant and a Review of the Literature. Prim Care Companion CNS Disord 2012, p 14.

65 Wang J, Greenberg H: Status cataplecticus precipitated by abrupt withdrawal of venlafaxine. J Clin Sleep Med 2013;9:715-716.

66 Cutler N: Severe Venlafaxine Withdrawal Successfully Treated With a Short Course of Duloxetine. Prim Care Companion CNS Disord 2017, p 19

67 Qadir A, Haider N: Duloxetine withdrawal seizure. Psychiatry (Edgmont) 2006;3:10.

68 Pitchot W, Ansseau M: Shock-like sensations associated with duloxetine discontinuation. Ann Clin Psychiatry 2008;20:175-175.

69 Hou YC, Lai CH: Long-term duloxetine withdrawal syndrome and management in a depressed patient. J Neuropsychiatry Clin Neurosci 2014;26:E04.

70 Williams GW, Gandhi SJ, Altamirano A: An acute neurological syndrome with cerebrovascular and parkinsonian clinical features associated with perioperative SNRI withdrawal. J Neurosurg Anesthesiol 2013;25: 353-354.

71 Fava GA, Cosci F, Offidani E, Guidi J: Behavioral toxicity revisited: iatrogenic comorbidity in psychiatric evaluation and treatment. J Clin Psychopharmacol 2016;36:550-553.

72 De las Cuevas C, de Leon J: Reviving research on medication attitudes for improving pharmacotherapy. Psychother Psychosom 2017; 86:73-79.

73 Fava GA, Guidi J, Rafanelli C, Rickels K: The clinical inadequacy of the placebo model and the development of an alternative conceptual framework. Psychother Psychosom 2017;86: 332-340.
74 Fava GA, Tomba E, Bech P: Clinical pharmacopsychology: conceptual foundations and emerging tasks. Psychother Psychosom 2017; 86:134-140.

75 Cosci F, Chouinard G, Chouinard V-A, Fava GA: The Diagnostic clinical Interview for Drug Withdrawal 1 (DID-W1): new symptoms of selective serotonin reuptake inhibitors (SSRI) or serotonin norepinephrine reuptake inhibitors (SNRI). Riv Psichiat 2018; 53:95-99.

76 Carvalho AF, Sharma MS, Brunoni AR, Vieta E, Fava GA: The safety, tolerability and risks associated with the use of newer generation antidepressant drugs. Psychother Psychosom 2016;85:270-288.

77 Fava GA: Can long-term treatment with antidepressant drugs worsen the course of depression? J Clin Psychiatry 2003;64:123-133.

78 Fava GA: Rational use of antidepressant drugs. Psychother Psychosom 2014;83:197204.

79 Schueler YB, Koesters M, Wieseler B, Grouven U, Kromp M, Kerekes MF, Kreis J, Kaiser T, Becker T, Weinmann S: A systematic review of duloxetine and venlafaxine in major depression, including unpublished data. Acta Psychiatr Scand 2011;123:247-265.

80 Maund E, Tendal B, Hróbjartsson A, Jørgensen KJ, Lundh A, Schroll J, Gøtzsche PC: Benefits and harms in clinical trials of duloxetine for treatment of major depressive disorder: comparison of clinical study reports, trial registries, and publications. BMJ 2014; 348:g3510.

81 Chouinard G, Samaha AN, Chouinard VA, Peretti CS, Kanahara N, Takase M, Iyo M: Antipsychotic-induced dopamine supersensitivity psychosis: pharmacology, criteria, and therapy. Psychother Psychosom 2017;86: 189-219.

82 Spielmans GI: Duloxetine does not relieve painful physical symptoms in depression: a meta-analysis. Psychother Psychosom 2008; $77: 12-16$ 